\title{
Hospital Advertisements in Newspapers, Is It Still Worth It?
}

\author{
Ashraf Ahmad Zaghloul ${ }^{1}$ \\ ${ }^{1}$ College of Health Sciences, University of Sharjah, United Arab Emirates \\ Correspondence: Ashraf Ahmad Zaghloul, Associate Professor, Health Services Administration, College of \\ Health Sciences, University of Sharjah, United Arab Emirates.
}

Received: February 6, 2017 Accepted: March 14, 2017 Online Published: March 27, 2017

doi:10.5539/gjhs.v9n5p27 URL: https://doi.org/10.5539/gjhs.v9n5p27

\begin{abstract}
Introduction: Marketing the hospital image through advertising shapes the sources of information upon which the patient takes a decision to purchase the service. Advertisement is considered to be one of the marketing activities geared towards promoting the hospital's image. The aim of this study is to explore and investigate the determinants of consumer behavior toward newspaper advertising eye-catchers for hospitals and medical care in the UAE.

Methodology: A cross-sectional study design was followed using the snowball technique to select a convenient sample of the population of Sharjah, UAE. The total number of questionnaires valid for statistical analysis accounted for a 402 .

Results: The significant adjusted odds included in the model were occupation (Administrative) $=2.1$ (CI 1.1-4.5), name and brand $=0.4$ (CI 0.1-0.8), clinical staff photo $=0.2$ (CI 0.1-0.7), and location $=3.9$ (CI 1.3-11.9).

Conclusion: Healthcare organizations are required to further assess the feedback of their marketing plans especially newspaper advertisement budgets through the quality control activities performed at these organizations.
\end{abstract}

Keywords: eye-catchers, newspaper advertisement, logistic regression

\section{Introduction}

Hospital marketing is a service activity that drives hospitals' medical services to the patient. Hospital marketing is beneficial to both; hospitals, as it brings business and promotes good image and to the public, as it promotes health and well-being through free health information, and reduces waste of medical resources through education on making correct choices in medical treatments. (Chen \& Kao, 2011)

Marketing the hospital image through advertising shapes the sources of information upon which the patient takes a decision to purchase the service. Sources of information besides advertising include; physician referrals, word-of-mouth from friends or relatives, and magazine articles. (Nowak \& Washburn, 1998)

Chen and Kao (2011) identified quality of medical services, accessibility of the medical, medical expenses, facilities and marketing promotion as important factors that influence consumers' choices for rendered medical services. Marketing promotion not only can improve the cognition of the medical services, satisfaction and trust, but also improve the customer loyalty towards the hospital. Therefore, if the hospital wants to improve the competition ability, it must try hard towards the factors that may influence the consumers' choices. (Chen \& Kao, 2011)

Advertisement is considered to be one of the marketing activities geared towards promoting the hospital's image. Advertisement could be through newspapers, television, and press conferences. Advertising research identify three types of domains of values perceived by the consumer for an ad to be valuable, the informative value of advertisements (Liao, Yen, \& Li, 2011), the financial reward value, and entertainment value. When ads are perceived to contain valuable information, users will elicit less irritation and avoidance. The information domain provides a valuable source on product alternatives that helps them with their purchase decisions. (Edwards, Li, \& Lee, 2002)

Another factor that may affect the perception to the ad is an ad's entertainment value, in terms of colours, design, logo, photos for either the staff or facility. (5) The third value would be the monetary benefits behind the ad, as studies have suggested, an individual interested in deriving monetary benefits from direct marketing programs also shows greater interest in the advertisement. (Chang, Rizal, \& Amin, 2013) 
The aim of this study is to explore and investigate the determinants of consumer behavior toward newspaper advertising eye-catchers for hospitals and medical care in the UAE.

\section{Material \& Methods}

\subsection{Study Design}

The study employed an exploratory cross-sectional, analytical study design.

\subsection{Study Population}

The study population included native and Arabic speaking residents within the Emirate of Sharjah, UAE.

\subsection{Sampling}

A convenient, non-probability sample was chosen. The snowball sampling technique was employed to select the participants included in the study. This technique is a special nonprobability method that is often used for hidden populations that are difficult for researchers to access or when the desired sample characteristic is rare. Snowball sampling relies on referrals from the initial subjects to generate additional subjects, thus the sample group appears to grow like a rolling snowball. Native and Arabic speaking expatriate participants were initially approached. The final sample size included a total number of 402 respondents. The data collection phase started on March 2016 and ended in May 2016. (Zaghloul \& Alsokair, 2008; Zaghloul, El Sergany, El Enein, Alsuwaidi, \& Ayub, 2014)

\subsection{Sample Size}

Based on unofficial reports regarding the proportion of Arabic newspaper readers in the UAE, which ranged between $14 \%$ to $22 \%$ the sample size was calculated accordingly.

Formula for sample size determination

$$
\mathbf{n}=\mathbf{N} * \mathbf{X} /(\mathbf{X}+\mathbf{N}-\mathbf{1})
$$

where, $\mathrm{X}=\mathrm{Z}_{\alpha / 2}{ }^{2} * \mathrm{p} *(1-\mathrm{p}) / \mathrm{MOE}$, and $\mathrm{Z}_{\alpha / 2}$ is the critical value of the Normal distribution at $\alpha / 2$, MOE is the margin of error, $\mathrm{p}$ is the sample proportion, and $\mathrm{N}$ is the population size.

Margin error $=5 \%$, Confidence level $=95 \%$, Estimated population $=500,000$ Arabic speaking residents, Population proportion estimation $=18 \%$. The calculated sample size $=384$.

Model $\mathrm{X}^{2}=24.2, p=0.004$ yielding a statistically significant model. Hosmer-Lemeshow Test $=8.8, p=0.35, \mathrm{R} 2=$ 0.25 , the model predicts $25 \%$ of the variance on the dependent variable.

Predicted correct percentage $=66.3 \%$, the overall percent of cases that are correctly predicted by the model.

\subsection{Data Collection Tool}

The study was conducted from the beginning of March 2016 until May 2016. Relevant data were collected through a structured questionnaire designed after reviewing the literature pertinent to the topic under study. The data were recorded using a predetermined format that entailed two main divisions. Division 1 included demographic items: age, gender, educational level, nationality, medical background. Division 2 included closed ended items related to the factors associated with advertisement about hospitals in UAE newspapers; frequency of reading newspapers, approval of hospital advertisement, eye-catching factors in a hospital advertisement, site of advertisement. Division 3 included closed ended items related to the main source of information and the image of the respondents' private hospital; the main source of information about the private hospital, second source of information, main characteristic about the hospital of choice.

\subsection{Statistical Analysis}

Statistical analysis was performed using Statistical Package for the Social Sciences (SPSS) software (v 21.0; IBM Corporation, Armonk, NY, USA). Data coding and entry were performed and variables with missing data were excluded from further statistical analysis.

\subsection{Ethical Considerations}

The research proposal was submitted for ethical approval by The Research Ethics Committee at the University of Sharjah, UAE. Both approvals were granted by February 2016, at which time the researchers began to conduct the study.

The respondents signed a written consent statement confirming that their participation in the study was of their own free will. The participants were informed of the option to refrain from joining the study or to withdraw at any phase of the data collection. The participants were informed through the consent form that all data collected would be kept confidential and destroyed after publication of the results of the study. 


\section{Results}

Table 1 shows the demographic characteristics of the sample under study by nationality. The highest percentage of UAE nationals accounted for those who were 40 years of age and above (58.3\%), where females accounted for the highest percent $(51.7 \%)$, with university education or below (72.0\%) while being working an administrative job accounted for more than half of the sample of UAE nationals (68.7\%). Slightly more than half of the sample of UAE nationals (51.7\%) read the newspapers twice/ week or more. Similarly, for Arabic speaking expatriates the highest percentage of the sample was accounted for 40 years of age and above (53.9\%), females $(58.1 \%)$, university education or below (74.9\%), and working an administrative job being $(55 \%)$. The highest percentage of Arabic speaking expatriates read the newspapers less than twice a week (51.3\%). The OR yielded a significant association between administrative jobs and nationality, $\mathrm{OR}=1.8$ (95\% CI 1.2-2.7).

Table 1. Demographic characteristics of the sample under study by nationality reading newspaper advertisements, (Dubai, 2016)

\begin{tabular}{|c|c|c|c|c|c|}
\hline & \multicolumn{2}{|c|}{$\begin{array}{l}\text { UAE National } \\
(\mathrm{n}=\mathbf{2 1 1})\end{array}$} & \multicolumn{2}{|c|}{$\begin{array}{l}\text { Arabic Speaking Expatriate } \\
(\mathrm{n}=191)\end{array}$} & \multirow[t]{2}{*}{ OR $(95 \% \mathrm{CI})$} \\
\hline & No. & $\%$ & No. & $\%$ & \\
\hline \multicolumn{6}{|l|}{ Age } \\
\hline$<40$ years & 88 & 41.7 & 88 & 46.1 & $0.8(0.5-1.2)$ \\
\hline $40+$ years & 123 & 58.3 & 103 & 53.9 & \\
\hline \multicolumn{6}{|l|}{ Gender } \\
\hline Male & 102 & 48.3 & 102 & 41.9 & $1.3(0.9-1.9)$ \\
\hline Female & 109 & 51.7 & 111 & 58.1 & \\
\hline \multicolumn{6}{|l|}{ Education } \\
\hline University level and below & 152 & 72.0 & 143 & 74.9 & $0.8(0.6-1.3)$ \\
\hline Postgraduate level & 59 & 28.0 & 48 & 25.1 & \\
\hline \multicolumn{6}{|l|}{ Occupation } \\
\hline Administrative & 145 & 68.7 & 105 & 55.0 & $1.8(1.2-2.7)$ \\
\hline Other & 66 & 31.3 & 86 & 45.0 & \\
\hline \multicolumn{6}{|l|}{ Rate of reading newspapers } \\
\hline$<2$ per week & 102 & 48.3 & 98 & 51.3 & $0.8(0.6-1.3)$ \\
\hline $2+$ per week & 109 & 51.7 & 93 & 48.7 & \\
\hline
\end{tabular}


Table 2 shows the odds of healthcare advertisement eye-catchers by the nationality reading the newspaper advertisement. The highest percentage of eye-catchers for UEA nationals were accounted for name and brand (70.6\%), clinical staff photos $(60.6 \%)$, slogan and logo (70.6\%), and relatives being the main source for choosing a private hospital $(52.3 \%)$. Whereas, the highest percentage of eye-catchers for Arabic speaking expatriates accounted for advertisement colours (50.5\%), clinical staff photos (53.8\%), slogan and logo $(71.0 \%)$, and location $(50.5 \%)$. No statistically significant association of advertisement eye-catchers with nationality were yielded.

Table 2 . Healthcare advertisement eye-catchers by the nationality reading newspaper advertisements, (Dubai, 2016)

\begin{tabular}{|c|c|c|c|c|c|}
\hline & \multicolumn{2}{|c|}{$\begin{array}{l}\text { UAE National } \\
(n=109)\end{array}$} & \multicolumn{2}{|c|}{$\begin{array}{l}\text { Arabic Speaking Expatriate } \\
(\mathrm{n}=93)\end{array}$} & \multirow[t]{2}{*}{ OR $(95 \% \mathrm{CI})$} \\
\hline & No. & $\%$ & No. & $\%$ & \\
\hline \multicolumn{6}{|c|}{ Name and Brand } \\
\hline Yes & 77 & 70.6 & 34 & 36.6 & $0.7(0.4-1.3)$ \\
\hline No & 32 & 29.4 & 59 & 63.4 & \\
\hline \multicolumn{6}{|c|}{ Advertisement colors } \\
\hline Yes & 46 & 42.2 & 47 & 50.5 & $1.4(0.8-2.4)$ \\
\hline No & 63 & 57.8 & 46 & 49.5 & \\
\hline \multicolumn{6}{|c|}{ Clinical Staff photos } \\
\hline Yes & 66 & 60.6 & 50 & 53.8 & $0.8(0.4-1.3)$ \\
\hline No & 43 & 39.4 & 43 & 46.2 & \\
\hline \multicolumn{6}{|c|}{ Slogan and logo } \\
\hline Yes & 77 & 70.6 & 66 & 71.0 & $1.0(0.5-1.9)$ \\
\hline No & 32 & 29.4 & 27 & 29.0 & \\
\hline \multicolumn{6}{|l|}{ Location } \\
\hline Yes & 42 & 38.5 & 47 & 50.5 & $1.6(0.9-2.8)$ \\
\hline No & 67 & 61.5 & 46 & 49.5 & \\
\hline \multicolumn{6}{|c|}{ Main source for private hospital of choice } \\
\hline Relatives & 57 & 52.3 & 43 & 46.2 & $1.3(0.7-2.2)$ \\
\hline Others & 52 & 47.7 & 50 & 53.8 & \\
\hline \multicolumn{6}{|c|}{ Second source for private hospital of choice } \\
\hline Close friends & 43 & 39.4 & 40 & 43.0 & $0.9(0.5-1.5)$ \\
\hline Others & 66 & 60.6 & 53 & 57.0 & \\
\hline
\end{tabular}


Table 3 shows the logistic regression model of the predictive variables for reading healthcare advertisements. The significant adjusted odds included in the model were occupation (Administrative) $=2.1$ (CI 1.1-4.5), name and brand $=0.4(\mathrm{CI} 0.1-0.8)$, clinical staff photo $=0.2(\mathrm{CI} 0.1-0.7)$, and location $=3.9(\mathrm{CI} 1.3-11.9)$.

Table 3. Logistic regression model of the predictive variables for reading healthcare advertisements, (Dubai, 2016)

\begin{tabular}{llllll}
\hline Variable & $\boldsymbol{\beta}$ & $\mathbf{S E} \boldsymbol{\beta}$ & $\mathbf{E x p}(\boldsymbol{\beta})$ & $\boldsymbol{p}$ & $\mathbf{9 5 \%} \mathbf{C I}$ \\
\hline Constant & -0.16 & 0.35 & 1.92 & 0.04 & \\
Occupation (Administrative) & 0.78 & 0.37 & 2.1 & 0.04 & $1.1-4.5$ \\
Name and Brand & -0.96 & 0.4 & 0.4 & 0.01 & $0.1-0.8$ \\
Clinical Staff photo & -1.39 & 0.5 & 0.2 & 0.005 & $0.1-0.7$ \\
Location & 1.4 & 0.6 & 3.9 & 0.02 & $1.3-11.9$ \\
\hline
\end{tabular}

Model $\mathrm{X}^{2}=24.2, \mathrm{p}=0.004, \mathrm{R}^{2}=0.25$, Hosmer - Lemeshow Test $=8.8, \mathrm{p}=0.35$

Predicted correct percentage $=66.3$.

\section{Discussion}

Once innovative electronic communication applications on computers and cellular phones came in reach to almost every person around the globe, everyone became overwhelmed with the ease, amount and promptness of acquisition of available data and information. Such new technological media are exerting enormous pressures on the traditional sources and media for information as television, newspapers, radio. In a parallel context, the same pressures are being implemented for posting or announcing advertisements, in fact the ground has become expandable and global for reaching the target population on the marketing plans for organizations around the world and the healthcare organizations are of no exception. Merges, acquisitions, and expansion mission statements are becoming to rely heavily on global strategic marketing plans and specifically on advertising campaigns. Yet, studies challenge the effectiveness of newspaper advertisements as it used to be versus innovative media including YouTube, websites, Facebook, and communication applications. (Carter-Harris, Bartlett, Warrick, \& Rawl, 2016; Hapca et al., 2014)

By mere observation the behavior in the Gulf region towards sources of information acquisition shows no difference as the region is deficient in research on the changing trends in sources of information and advertisement utilization. Results yielded a significant association with newspaper advertisement reading with administrative jobs for both UAE nationals and expatriate Arabic speaking readers as a result of the purchase of daily newspapers at every governmental and non-governmental organizations firm all over the UAE as part of the fringe benefits offered to the employees. The conservative nature and the strong family bonds among the people in the gulf region brings about the word-of-mouth an essential and trustful source for information acquisition. This could support the high percentage of relatives being the main source for hospital choice among UAE nationals. Whereas, besides the main eye-catchers for advertisements including brand, colors, and clinical staff photos, location appears to be an important eye-catcher for Arabic speaking expatriates. The high cost of living in UAE and the limited services on health insurance plans for expatriates could be a reason behind the high percentage, and a determinant on the logistic regression model accounted for location, as a means for minimizing expenses among expatriate families. Name and brand as well as clinical staff photos show the consistent yield as newspaper advertisement eye-catchers for healthcare organizations as reported in other studies. (Xu et al., 2015; Braun, Mejia, Barnoya, Gregorich, \& Perez-Stable, 2011)

\section{Conclusion}

Healthcare organizations are required to further assess the feedback of their marketing plans especially newspaper advertisement budgets through the quality control activities performed at these organizations. Posing an important strategic question to answer, whether to continue utilizing the traditional media for advertisement or is it time to change with the changing world around us.

\section{Limitations}

The convenience sampling technique followed poses implications on the generalizability and precision of the results yielded from the study. Being an exploratory study, the sample size would be another determinant towards generalization of the results. 


\section{Competing Interests Statement}

The author declares no conflicts of interest in this work either financial or scientific with any organization. This research received no specific grant from any funding agency in the public, commercial, or not-for-profit sectors. The author alone is responsible for the content and writing of the paper.

\section{Funding}

The study has been carried out without external funding.

\section{References}

Braun, S., Mejia, R., Barnoya, J., Gregorich, S. E., \& Pérez-Stable, E. J. (2011). Tobacco advertising and press coverage of smoking and health in 10 years of Argentinean newspapers. CVD Prev Control, 6(3), 71-80. https://doi.org/10.1016/j.cvdpc.2011.04.002

Carter-Harris, L., Bartlett Ellis, R., Warrick, A., \& Rawl, S. (2016). Beyond Traditional Newspaper Advertisement: Leveraging Facebook-Targeted Advertisement to Recruit Long-Term Smokers for Research. J Med Internet Res., 18(6), e117. https://doi.org/10.2196/jmir.5502

Chang, H. H., Rizal, H., \& Amin, H. (2013). The determinants of consumer behavior towards email advertisement. Internet Research, 23(3), 316-337. https://doi.org/10.1108/10662241311331754

Chen, C. B., \& Kao, P. L. (2011). The Effects of the Hospital Marketing Promotion on Consumers' Choice of Hospitals Consumers. The Journal of Human Resource and Adult Learning, 7(2).

Edwards, S. M., Li, H., \& Lee, J. H. (2002). Forced exposure and psychological reactance: antecedents and consequences of the perceived intrusiveness of pop-up ads. Journal of Advertising, 31(3), 83-95. https://doi.org/10.1080/00913367.2002.10673678

Hapca A, Jennings CG, Wei L, Wilson A, MacDonald TM, Mackenzie IS. Effectiveness of newspaper advertising for patient recruitment into a clinical trial. $B r \quad J$ Clin Pharmacol, 77(6), 1064-72. https://doi.org/10.1111/bcp.12262

Liao, C. H., Yen, H. R., \& Li, E.Y. (2011). The effect of channel quality inconsistency on the association between e-service quality and customer relationships. Internet Research, 24(4), 458-478. https://doi.org/10.1108/10662241111158326

Nowak, L. I., \& Washburn, J. H. (1998). Patient sources of information and decision factors in selecting cosmetic surgeons. Health Marketing Quarterly, 15(4), 45-54. https://doi.org/10.1300/J026v15n04_03

Xu, X., Gong, T., Zhang, Y., Wu, C., Xie, Y. J., Wang, H. H., Zhu, R., Li, W., An, L., \& Zhao, Y. (2015). Evaluation of anti-smoking television advertising on tobacco control among urban community population in Chongqing, China. Tob Induc Dis., 13(1), 31. https://doi.org/10.1186/s12971-015-0057-4

Zaghloul, A. A., \& AlSokair, M. K. (2008). Constructing a nurse appraisal form: A Delphi technique study. $J$ Multidisciplinary Healthcare, 1, 1-14.

Zaghloul, A. A., El Sergany, M., El Enein, N., Alsuwaidi, H., \& Ayub, M. (2014). Over-the-counter medication patterns in households in Sharjah, UAE. Risk Management and Healthcare Policy. 7, 19-24. https://doi.org/10.2147/RMHP.S55752

\section{Copyrights}

Copyright for this article is retained by the author(s), with first publication rights granted to the journal.

This is an open-access article distributed under the terms and conditions of the Creative Commons Attribution license (http://creativecommons.org/licenses/by/4.0/). 